\title{
FUNCELASE - AN EFFICIENT PREPARATION FOR THE ISOLATION OF REVERSION COMPETENT PROTOPLASTS FROM YEASTS.
}

K. Kavanagh and P.A. Whittaker,

Department of Biology, Maynooth College, Co. Kildare, Ireland.

\section{SUMMARY.}

The lytic preparation Funcelase was shown to be capable of releasing protoplasts from exponential phase cells of Candida albicans, Kluyveromyces lactis, Saccharomyces cerevisiae, Saccharomycopsis fibuligera and Schizosaccharomyces pombe. The protoplasts so produced displayed reversion frequencies far superior to those isolated by treatment with Novozym 234 or Suc d'Helix pomatia.

\section{INTRODUCTION.}

Yeast protoplasts suitable for fusion, transformation or cloning studies may be isolated by the enzymatic degradation of the cell wall. Eddy and Williamson (1957) first demonstrated the release of protoplasts from exponential phase cells of Saccharomyces carlsbergensis using "snail gut juice". This preparation is now commercially available as Suc d'Helix pomatia (IBF Biotechnics, France) and contains $\alpha$-D-glucanase and $\beta$-D-glucanase activities (Hamlyn et al., 1981). Over the years many other lytic preparations have entered the market (Peberdy, 1985) but one of the most frequently employed has been Novozym 234 (Novo Biolabs., Denmark), previously known as Mutanase. This is capable of liberating protoplasts from a wide range of yeasts (Stephen \& Nasim, 1981; Dickinson \& Isenberg, 1982) and filamentous fungi (Quigley et al., 1987; Collings et al., 1988) and displays $\alpha$-D-glucanase, $\beta-D$ glucanase, chitinase and protease activity (Hamlyn et al., 1981). Recently a new lytic preparation, Funcelase (Yakult Honsha Co. Ltd., Japan), has become available. This is produced by a strain of Trichoderma viride and contains $\beta$-D-glucanase and chitinase activities. In preliminary studies it was shown to be capable of releasing protopiasts 
from filamentous fungi and the yeasts $S$. cerevisiae and Candida utilis (Ogawa et al., 1979).

The objective of the work described here was to investigate the potential of Funcelase for releasing protoplasts from a range of yeasts and to establish if the protoplasts so produced displayed enhanced reversion capabilities compared to those liberated by Novozym or Suc d'Helix pomatia treatment.

\section{MATERIALS AND METHODS.}

Organisms: The yeasts employed in this work were Candida albicans ATCC 44990 (ade, thr), Kluyveromyces lactis 102 (arg), Saccharomyces cerevisiae JJ1A (arg*, thr), Saccharomycopsis fibuligera CBS 5158 and Schizosaccharomyces pombe 501 Cultivation conditions: Yeasts were grown in $200 \mathrm{ml}$ YEPD $(2 \%(\mathrm{w} / \mathrm{v})$ glucose (BDH), $2 \%$ (w/v) Bactopeptone (Difco) and 1\% (w/v) Yeast Extract (Oxoid)) in $500 \mathrm{ml}$ conical flasks at $30^{\circ} \mathrm{C}$ and $200 \mathrm{rpm}$ in an orbital incubator. Osmotically stabilised buffer: Membrane integrity was ensured by maintaining protoplasts in an isotonic environment. Potassium chloride at a concentration of $0.5 \mathrm{M}$ or $0.9 \mathrm{M}$ was determined to be optimum for protoplasts of C. albicans and Sacch. fibuligera, respectively. Sorbitol was used at the following concentrations: $1.1 \mathrm{M}$ for protoplasts of $K$. lactis, $0.8 \mathrm{M}$ for those of $S$. cerevisiae and $0.9 \mathrm{M}$ for those of Sch. pombe. In addition to an osmotic stabiliser, the buffer also contained $0.1 \mathrm{M}$ sodium chloride and $0.1 \mathrm{M}$ acetic acid. The $\mathrm{pH}$ was adjusted to 5.5 by the addition of $0.1 \mathrm{M}$ sodium hydroxide prior to autoclaving.

Protoplast isolation: Exponential phase cells of each yeast were harvested by centrifugation, washed and resuspended at a density of $3 \times 10^{7} / \mathrm{ml}$ in $6 \mathrm{ml}$ of the appropriate osmotically stabilised buffer containing either $1.5 \mathrm{mg} / \mathrm{ml}$ Funcelase, 1.5 $\mathrm{mg} / \mathrm{ml}$ Novozym or $0.032 \mathrm{ml} / \mathrm{ml}$ Suc d'Helix pomatia. Incubation was at $30^{\circ} \mathrm{C}$ for 45 minutes. Protoplasts were subsequently harvested and washed with isotonic buffer prior to being resuspended in $2 \mathrm{ml}$ of the same buffer.

Protoplast reversion: Protoplasts were induced to revert to the cellular state by embedding approximately $1 \times 10^{3}$ in molten $\left(48^{\circ} \mathrm{C}\right)$ osmotically stabilised YEPD containing $3 \%(\mathrm{w} / \mathrm{v})$ Bactoagar (Difco). Plates were incubated at $30^{\circ} \mathrm{C}$ for 4 days. The reversion rate was calculated as the percentage of protoplasts capable of colony formation under these conditions. The percentage of cells remaining in the protoplast population was determined by embedding in unstabilised reversion medium where only intact, osmotically stable cells could develop.

\section{RESULTS AND DISCUSSION.}

Exponential phase cells of each of the five yeast species were harvested and treated with the lytic preparations as described. The data from these experiments (Table 1) indicate that the three preparations are capable of converting large numbers of cells of each yeast into protoplasts. The actual degree of conversion varies depending upon the lytic preparation employed and the species under examination. In general, treatment of cells with Funcelase ensured the greatest degree of conversion to protoplasts although the results for Sch. pombe are at variance with this trend.

Microscopic examination of the protoplasts of $C$. albicans, S. cerevisiae and Sch. 
pombe produced by the action of Funcelase revealed the presence of large numbers of spheroplasts. These displayed the cellular morphology in isotonic buffer and retained wall fragments on their surface. Observations on the Funcelase induced conversion of cells to protoplasts in these yeasts indicated that spheroplasts constituted an intermediate stage in the transition process. In contrast, treatment of the same yeasts with Novozym 234 or Suc d'Helix pomatia resulted in a direct cell-protoplast transition, protoplasts being exuded through lytic enzyme- created pores in the cell wall.

$\begin{array}{lllll}\text { Yeast } & & \text { Funcelase } & \text { Novozym 234 } & \text { Suc d'Helix pomatia } \\ \text { C. albicans } & \text { Protoplasts (\%) } & 96.67 \pm 0.87 & 88.27 \pm 1.15 & 50.28 \pm 3.91 \\ & \text { Reversion (\%) } & 49.68 \pm 3.60 & 28.73 \pm 1.49 & 17.97 \pm 1.61 \\ \text { K. lactis } & \text { Protoplasts (\%) } & 100.0 \pm 0.0 & 99.33 \pm 0.91 & 63.50 \pm 2.69 \\ & \text { Reversion (\%) } & 34.23 \pm 1.31 & 2.02 \pm 0.31 & 13.29 \pm 0.58 \\ \text { S. cerevisiae } & \text { Protoplasts (\%) } & 100.0 \pm 0.0 & 100.0 \pm 0.0 & 97.86 \pm 0.95 \\ & \text { Reversion (\%) } & 83.96 \pm 2.05 & 8.16 \pm 0.95 & 18.19 \pm 0.61 \\ \text { Sacch. fibuligera } & \text { Protoplasts (\%) } & 100.0 \pm 0.0 & 100.0 \pm 0.0 & 97.65 \pm 0.61 \\ & \text { Reversion (\%) } & 19.81 \pm 2.01 & 2.65 \pm 0.14 & 2.33 \pm 0.34 \\ \text { Sch. pombe } & \text { Protoplasts (\%) } & 84.47 \pm 1.91 & 100.0 \pm 0.0 & 89.62 \pm 1.03 \\ & \text { Reversion (\%) } & 32.15 \pm 2.96 & 0.66 \pm 0.13 & 6.63 \pm 1.88\end{array}$

TABLE 1: The liberation of protoplasts from yeasts using various lytic preparations. (All values are the mean of seven determinations \pm S.D.)

The reversion rates of protoplasts liberated by Funcelase are substantially greater than those achieved by protoplasts released by Novozym 234 or Suc d'Helix pomatia treatment (Table 1). In the case of $S$. cerevisiae almost $85 \%$ of the protoplasts produced by the action of Funcelase were found to be reversion competent. It is proposed that this may be due to the presence of large numbers of spheroplasts in the Funcelase-liberated population facilitating an elevated reversion frequency. Alternatively, the enhanced reversion rates may be attributable to the fact that Funcelase is a relatively pure lytic preparation (Ogawa et al.,1979.) in contrast to Novozym 234 which has been shown to possess considerable amounts of proteolytic activity (Hamlyn et al., 1981) that have been implicated in retarding the reversion 
process by causing yeast protoplast membrane damage (O'Brien \& Whittaker, 1990).

Chemically-induced protoplast membrane perturbation has previously been implicated in abberant cell wall regeneration and reduced reversion to the cellular state (Legge \& Brown, 1988).

The data presented here indicate that Funcelase is an efficient preparation for the isolation of large populations of reversion-competent protoplasts from exponential phase cells of a range of yeasts. The superior reversion ability of Funcelase derived protoplasts should assist in the recovery of hybrid or transformant cells from protoplasts.

\section{ACKNOWLEDGEMENTS.}

The authors are grateful for financial assistance provided by Eolas (The Irish Science and Technology Agency).

\section{REFERENCES.}

Collings, A., Davis, B. and Mills, J. (1988). Microbios 53: 197-210. Dickinson, D.P. and Isenberg, I. (1982). J. Gen. Microbiol. 128: 651-654. Eddy, A.A. and Williamson, D.H. (1957). Nature (London) 179: 1252-1253. Hamlyn, P.F., Bradshaw, R.E., Mellon, F.M., Santiago, C.M., Wilson, J.M. and Peberdy, J.F. (1981). Enzyme Microb. Technol. 3: 321-325.

Legge, R.L. and Brown, R.M. (1988). Protoplasma 143: 38-42.

O'Brien, G.A. and Whittaker, P.A. (1990). Biochem. Soc. Trans. 18: 328-329.

Ogawa, K., Toyama, H. and Toyama, N. (1979) Bull. Fac. Agric. Miyukai Univ. 26: 387-398.

Peberdy, J.F. (1985) in "Fungal Protoplasts: Applications in Biochemistry and Genetics." Ed: J.F. Peberdy and L. Ferenczy. (Marcel Dekker Inc., New York.) 31-44.

Quigley, D.R., Taft, C.S., Stark, T. and Selitrennikoff, C.P. (1987). Exp. Mycol. 11: 236-240.

Stephen, E.R. and Nasim, A., (1981). Can. J. Microbiol. 27: 550-553. 